\title{
Human Factors: The Dirty Dozen in CTG misinterpretation
}

\author{
Obianuju Nzelu ${ }^{1 *}$, Edwin Chandraharan ${ }^{2}$ and Susana Pereira ${ }^{1}$ \\ ${ }^{1}$ Kingston Hospital NHS Foundation Trust, UK \\ ${ }^{2}$ St George's Hospital NHS Foundation Trust, Uk \\ Submission: August 16, 2018; Published: October 11, 2018 \\ *Corresponding author: Obianuju Nzelu, Kingston Hospital NHS Trust, Galsworthy Road, London, KT2 7QB; Email: Obianuju.nzelu@nhs.net
}

\begin{abstract}
The contribution of human factors to errors and adverse outcomes within most healthcare systems cannot be underestimated. In Obstetrics we rely on the cardiotocograph as a non-invasive tool for detecting fetal hypoxia. However, since its introduction in 1960 the CTG has failed to reduce the rate of hypoxia-induced perinatal morbidity and mortality. The recent Each Baby Counts report indicates that $62 \%$ of stillbirths, neonatal deaths, and brain injuries of term babies in labour in 2015 were related to errors in CTG interpretation and management. This carries a significant financial burden as recent figures from the National Health Service Litigation Authority (NHSLA) show that Obstetrics makes up 50\% of the total value of negligence claims in the UK.

The aim of this review is to explore the different aspects of human factors and how each contributes to CTG misinterpretation. We will be using a framework devised by Gordon DuPont called the Dirty Dozen. These are the 12 most common causes of error within aviation maintenance: Lack of communication, complacency, lack of knowledge, distraction, lack of teamwork, fatigue, lack of resources, pressure, lack of assertiveness, stress, lack of awareness, norms. We will discuss each of these and apply them to common CTG misinterpretation themes. Obstetrics is a highly pressured and often unpredictable specialty and, because of these human factors and the working environment, CTG interpretation errors occur. We believe that the solution to reducing errors is 2 -fold;
\end{abstract}

a) increasing use of Human Factors sciences and

b) Improving understanding of the fetal physiology that underpins CTG appearances.

Keywords: Human factors; Obstetrics; cardiotocograph; Healthcare; Labour ward; Training; Guideline

Abbreviations: CTG: Cardiotocograph; NHSLA: National Health Service Litigation Authority; CESDI: Confidential Enquiry into Stillbirths and Deaths in Infancy; SROM: Spontaneous rupture of membranes; NCT: National Childbirth Trust

\section{Introduction}

Human factors, often referred to as ergonomics, is an established scientific discipline used in many other safety critical disciplines [1], such as the aviation industry. It can be defined as the link between knowledge, the environment in which we work, personal circumstances, and communication between team members. Nowadays, in the Western World, most accidents and untoward outcomes are rarely due to a lack of resources. They are more likely due to human factors. The aviation industry and Obstetrics have as many similarities as differences. There is cross learning to be had from both disciplines, but inevitable adaptations need to be made. Both operate in highly technical environments, with highly specialized and multidisciplinary teams where the outcomes are expected to be good. In both aviation and maternity, accidents are rare, mostly unexpected, and very tragic events.

Cardiotocograph (CTG) is a non-invasive tool for the assessment of fetal wellbeing in labour. When interpreted and acted on correctly the CTG enables timely delivery to avoid hypoxic damage to the fetus, and it also prevents unnecessary intervention. However, 50 years after its introduction to clinical practice there is a wide range of subjective difference in the classification of CTGs [2]. In the National Health Service Litigation Authority (NHSLA) Obstetrics accounts for $50 \%$ of the total value of claims received [3]. Data shows that although the number of claims brought forward for cerebral palsy has remained stagnant, the amount paid out for this type of claim continues to increase 220 claims in 2013-2014 with a claim amount $>£ 733$ million, 188 claims in 2015-2016 with a total amount of $>£ 989$ million.

The recent Each Baby Counts report analysed complete data relating to term stillbirths, neonatal deaths, and babies with brain injuries born following labour in 2015 in the UK. Fetal monitoring was highlighted as a commonly recurring contributory factor to these outcomes [4]. The problem is not new, in the Confidential Enquiry into Stillbirths and Deaths in Infancy (CESDI) 1997 
report, again most of the criticism focused on electronic fetal monitoring [5].

In the last two decades there has been an emphasis on improving guidelines and training in the use of CTG to reduce hypoxia-induced perinatal morbidity and mortality. This was largely driven by recommendations from the CESDI report, which called for regular/rolling CTG teaching and simple guidelines on the interpretation, recognition, and communication of abnormal CTGs. The Each Baby Counts report goes further and highlights human factors as a major cause of error in CTG interpretation. This article aims to explore the different arms of human factors and how each relates to CTG interpretation. We will be using a framework devised by Gordon DuPont who was the first president of the Pacific Aircraft Maintenance Engineers Association [6]. He identified the 12 most common causes of maintenance personnel making an error in judgment, which ultimately results in a maintenance error. He called them the Dirty Dozen Errors in Maintenance [7] (Figure 1). In this article we will discuss each of the Dirty Dozen and apply them to common CTG misinterpretation themes. We will also discuss ways in which these might be mitigated or avoided in practice.

Gordon DuPont's Dirty Dozen

\section{Lack of communication}

2. Complacency

3. Lack of knowledge

4. Distraction

5. Lack of teamwork

6. Fatigue

7. Lack of resources

8. Pressure

9. Lack of assertiveness

10. Stress

11. Lack of awareness

12. Norms

Figure 1: Dupont's Dirty Dozen.

\section{The Dirty Dozen}

\section{Lack of communication}

Communication is the exchange of information and transference of meaning between individuals. In the context of CTG interpretation this often falls into either confirmation bias e.g. "this trace looks normal, don't you think?"; or lack of appropriate escalation. Strategies to improve good communication include breaking down boundaries between members of the multidisciplinary team so that even the most junior member of staff can feel comfortable approaching the most senior clinician to ask for help. Structured messages are also designed to avoid missing important things and tend to be useful for documentation and for hand over, especially in the context of shift work - as happens on most labour wards. The best known tool is SBAR which stands for S - situation, B - background, A- assessment and R-recommendation, or specifically for CTG documentation the mnemonic DRCBrVADO (Figure 2).

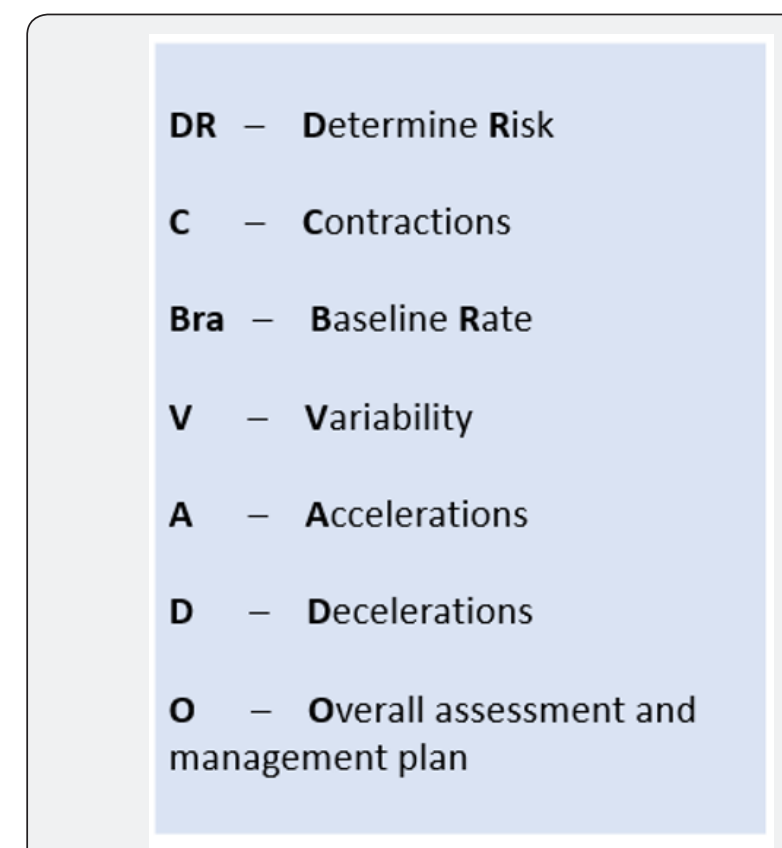

Figure 2: DRCBrVADO.

\section{Complacency}

This insidious cause of error usually occurs as people become overconfident and rely on pattern recognition for CTG interpretation "I've seen this before and it was fine, it must be fine now". It is easy to become complacent when using pre-designed stickers to define CTGs as you are less likely to take in the whole clinical picture and think of the physiology behind CTG changes [8]. For example, the same pattern on the CTG may be of different significance depending on the gestational age, the stage of labour, or the presence of meconium. This human factor is mitigated by reading each CTG individually, and in context of the specific woman and baby. Changing the language from "How is the CTG trace?" to "How is the baby?" may be a first step in encouraging clinicians to contextualise that particular fetus.

\section{Lack of knowledge}

On the whole clinicians are better at recognising hypoxic stress because decelerations are both audible and visible on the CTG. However, there is a lack of understanding of other causes of encephalopathy and neonatal death, such as anemia and sepsis, and how they manifest on the CTG (Figure 3). Training is the best safety net to address this human factor. The Each Baby Counts initiative called for maternity units to introduce 


\section{Global Journal of Reproductive Medicine}

annual mandatory CTG training before independent practice on labour wards. Within the training there must be an emphasis on understanding fetal physiology and how physiological changes are transcribed onto the CTG [9] (Figure 3), Chorioamnionitis: Increasing baseline fetal heart rate in the absence of significant decelerations should prompt the suspicion of chorioamnionitis. The term "uncomplicated tachycardia" gives false reassurance and should be avoided. In the presence of chorioamnionitis, delivery should be expedited if not imminent and superimposed hypoxic stress should be avoided.

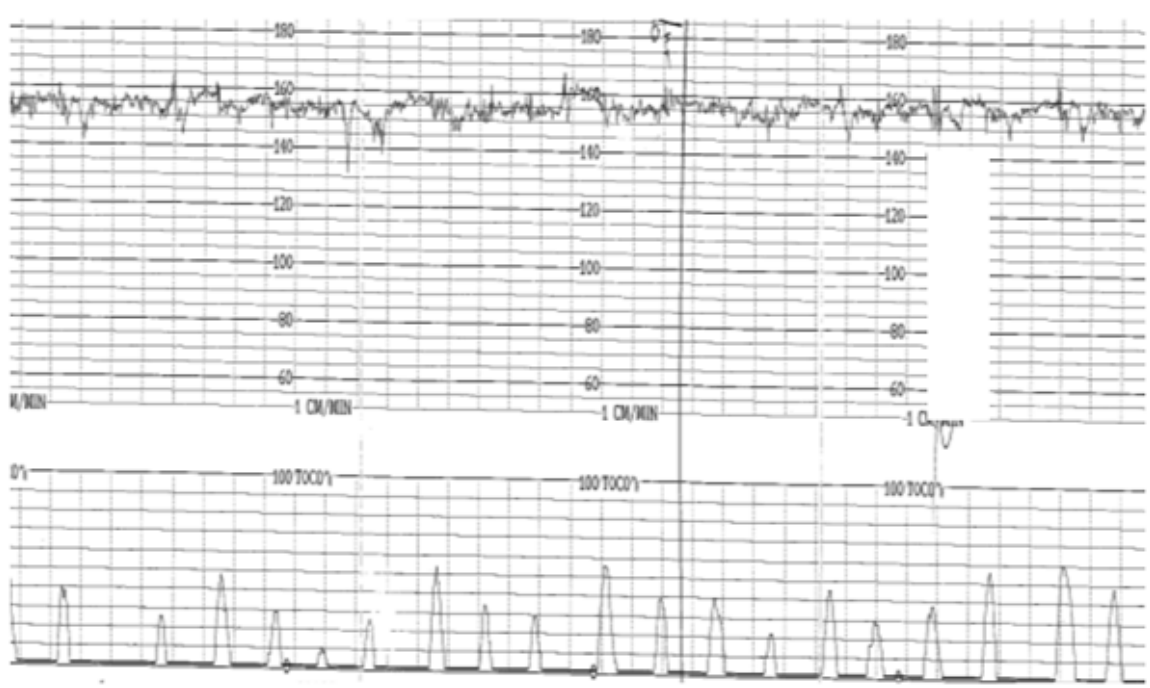

Figure 3: Case of chorioamnionitis at 40 weeks gestation for example, an increasing baseline fetal heart rate in the absence of significant decelerations should prompt the suspicion of chorioamnionitis. The term "uncomplicated tachycardia" gives false reassurance and should be avoided. In the presence of chorioamnionitis, delivery should be expedited if not imminent and superimposed hypoxic stress should be

\section{Distraction}

This is anything that takes your mind off a task even for a second. Our minds work faster than our hands, so a distraction can very quickly steer you away from the task at hand. On the labour ward it is important to maintain a helicopter view of events and if we are distracted or committed to a specific task that needs our full attention, it is important to hand the helicopter view role to another member of the team. Taking care of a patient in labour involves multiple tasks and placement of an epidural is typically the time when the CTG is neglected. Epidural analgesia can lead to maternal hypotension and consequently uterine hypoperfusion with potential acute hypoxic stress to the fetus. Awareness of the importance of monitoring during epidural placement and the use of centralised electronic CTG monitoring systems can help to mitigate these risks.

\section{Lack of teamwork}

The labour ward is made up of a large multidisciplinary team however, the individuals within the team change frequently. Consequently, we often work with people we have not worked with before. This makes it difficult to know everyone, how they work, and their strengths and limitations. For example, when managing a cord prolapse with prolonged fetal deceleration, delivery needs to be accomplished in the quickest and safest way. There should be clear delegation and division of roles to ensure a swift and co-ordinated resolution. This human factor can be mitigated by doing introductions at the start of each shift and conducting multidisciplinary simulation training on a regular basis.

\section{Fatigue}

Fatigue is a feeling of tiredness, reduced energy, and increased effort to perform tasks effectively and without errors [10]. This is particularly, but not exclusively, relevant to night shifts because human beings operate on a circadian rhythm where we are programmed to be awake in the day and asleep at night. In the aviation industry the hours between 2am and 6am are referred to as the "Window of Circadian Low" or WOCL, as it is the time when alertness and performance are most degraded [11]. In maternity this probably corresponds to a peak of activity. Recent research by University College London, University of London, and the National Childbirth Trust (NCT) found that more than $50 \%$ of births following spontaneous labour occur between $1 \mathrm{am}$ and $7 \mathrm{am}$ with a peak around 4am [12]. This human factor can be mitigated by adjusting staffing to levels of activity within each unit and providing facilities for rest breaks during shifts. Also, the use of a "Fetal Monitoring Checklist" can reduce the risk of missing preexisting fetal injury (Table 1) [13]. Forming a habit of asking these questions before reviewing all CTGs will help avoid this common pitfall, particularly when fatigued.

\section{Lack of Resources}

As mentioned previously most errors in Western healthcare 


\section{Global Journal of Reproductive Medicine}

are not due to a lack of resources.

Table 1: Pereira S, Chandraharan E [13] Recognition of chronic hypoxia and pre-existing foetal injury on the cardiotocograph (CTG).

\begin{tabular}{|c|c|}
\hline 1 & Baseline foetal heart rate appropriate for gestation \\
\hline 2 & Confirm normal variability and cycling \\
\hline 3 & $\begin{array}{c}\text { Confirm presence of accelerations (if not in labour/early } \\
\text { labour) }\end{array}$ \\
\hline 4 & Exclude shallow/late decelerations \\
\hline 5 & $\begin{array}{c}\text { Consider the wider clinical picture: meconium, temperature, } \\
\text { foetal growth, chorioamnionitis }\end{array}$ \\
\hline
\end{tabular}

However, if stocks are not diligently checked and maintained before they are required errors can occur as a result. Regarding CTG interpretation, if the abdominal probe is not adequately recording the fetal heart rate it might be necessary to site a fetal scalp electrode. Although these may not be used on every shift, they are an important piece of equipment to have readily available. A complimentary problem is not the lack but the inadequate use of resources and equipment available. A typical problem on CTG monitoring is the Inadvertent use of paper scales to which staff are unaccustomed. For example, at $3 \mathrm{~cm} / \mathrm{min}$ variability appears reduced to a clinician familiar with the $1 \mathrm{~cm} / \mathrm{min}$ scale leading to erroneous interpretation of the CTG. Most countries throughout the world, including the UK, use $1 \mathrm{~cm} / \mathrm{min}$ paper scales, the Netherlands use $2 \mathrm{~cm} / \mathrm{min}$, and North America and Japan use 3 $\mathrm{cm} / \mathrm{min}$. CTG machines also have a button to change the paper speed that can easily be inadvertently pushed when cleaning the machine.

\section{Pressure}

It is often presumed that pressure is mainly from the environment in which we work. However, many pressure-caused errors are due to self-pressure, where there is a false perception that we will be seen as incompetent if we ask for help. This human factor is mitigated by practicing effective prioritisation and delegation of tasks and asking for help when help is needed; even if this means escalation to senior members of the team who are off-site.

\section{Lack of assertiveness}

An example of lack of assertiveness is failing to speak up when things don't seem right. This is most evident in departments where there is a strong system of hierarchy. For example, a junior midwife who is not comfortable approaching the consultant to review a CTG. They may prefer to wait for a senior midwife to become available, thereby delaying review of a potentially pathological trace. This human factor is mitigated by breaking down this "chain of command" culture and building a team where juniors can approach seniors without reproach.

\section{Stress}

Stress is the subconscious response to the demands placed upon us. This does not only relate to the working environment but our personal lives also. Stress can lead to errors when it is excessive as it acts as a distraction and reduces concentration levels when performing complex tasks such as CTG interpretation. This human factor is mitigated by maintaining awareness of it and finding ways to destress; whether it be taking time off work, exercising the body or relaxing the mind. Some hospitals have introduced initiatives to promote physical exercise, mindfulness and yoga to promote staff well-being and reduce medical error.

\section{Lack of awareness}

Lack of awareness occurs when there is a lack of alertness and vigilance. This human factor is closely linked with complacency. For example, when monitoring a twin pregnancy in labour a common error is monitoring the same twin twice, not noticing that both CTG traces are similar and from the same fetus, leaving one twin unmonitored. Situational awareness is also about our mental picture of what is happening around us and how it will evolve. An example again with twins, where after the delivery of twin one the doctor becomes fixated on the repair of a bleeding episiotomy without noticing the abnormal CTG of the second twin. Haemostasis of a vascular episiotomy can be achieved by simply clamping vessels or compression with a swab, leaving time and space to prioritise twin 2 . Strategies to mitigate lack of situational awareness include promoting frequent safety huddles and avoiding single task fixation. Common contributors to loss of situation awareness have been already discussed such as lack of knowledge, stress, and fatigue.

\section{Norms}

Norms are unwritten rules followed or tolerated by most of the group, but negative norms can detract from as established safety standard. For example, the term "second stage CTG" is a negative norm sometimes used to classify CTGs. It implies a higher level of tolerance for a pathological trace on the anticipation that the baby will be shortly delivered. This is a dangerous practice and the guidelines for interpretation of the CTG in the first or second stage are the same. The second stage of labour brings an additional risk into the fetal monitoring: it becomes harder to monitor the fetal heart due to its low position in the pelvis; therefore, the risk of recording maternal pulse increases (Figure 4). It is unusual for a fetus to have accelerations during the second stage of labour, so if an improvement on the CTG trace or accelerations are noted in the second stage, especially if synchronous with contractions, it should be assumed that maternal heart rate is being monitored until proven otherwise. The use of a fetal scalp electrode instead of an abdominal transducer helps to mitigate this risk of confusing maternal with fetal pulse, leaving the fetus unmonitored in the latest phase of labour.

\section{Conclusion}

Obstetric practice and CTG interpretation put individuals, teams, and organisations under great pressure to make difficult decisions in dynamic and often unpredictable circumstances [3]. This combination of factors lead to errors in CTG interpretation. 


\section{Global Journal of Reproductive Medicine}

We believe that current guidelines and CTG training should focus on the following:

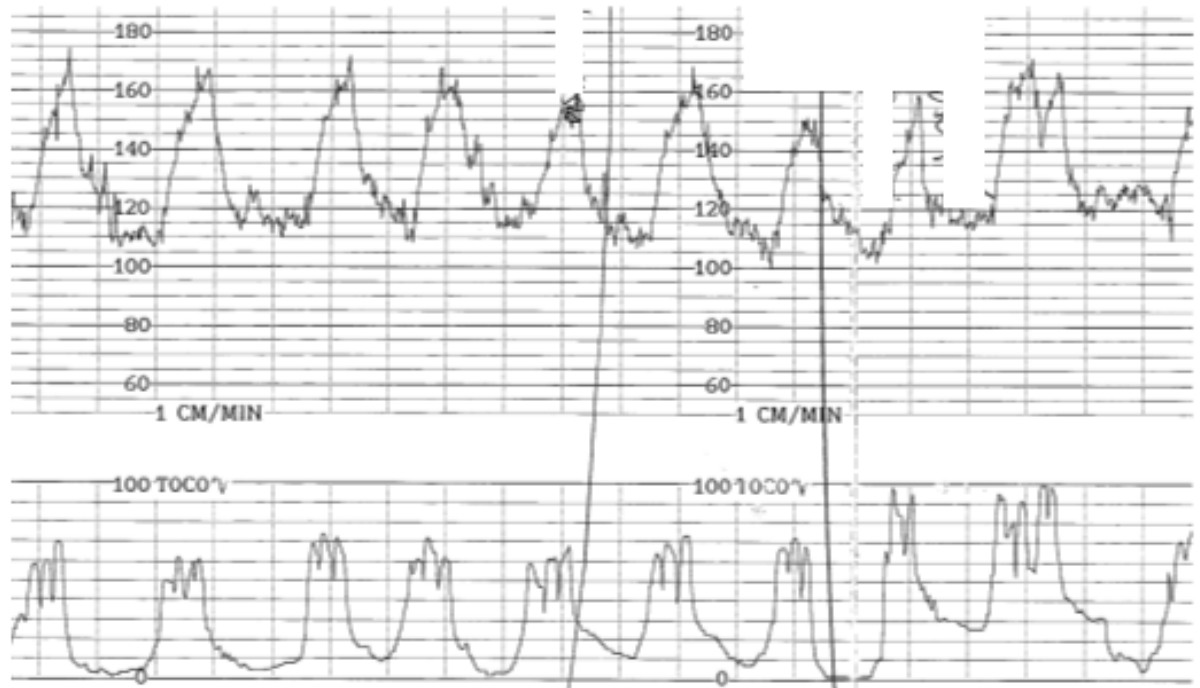

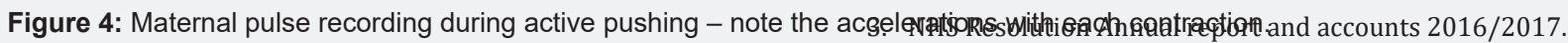

i. $\quad$ Fetal physiology and the physiological processes that underpin CTG appearances;

ii. the way in which human factors affect decision making. This is the key to reducing perinatal morbidity and mortality from intrapartum insults. Thus, the key points from this article in relation to CTG interpretation are as follows:

- $\quad$ Take in the whole picture when reviewing CTGs. Ask "how is the baby?", not the CTG!

- Understand the physiology behind CTG changes, including the changes caused by infection/ inflammation, not only hypoxia.

- Break down hierarchical boundaries, feel free to ask and escalate

- Avoid negative norms such as "uncomplicated tachycardia" and "second stage CTG"

\section{Declarations}

The authors declare that they have no competing interests. References

1. Human Factors in Healthcare: A Concordat from the National Quality Board. NHS England.

2. Rei M, Tavares S, Pinto P, Machado AP, Monteiro S, et al. (2016) Interobserver agreement in CTG interpretation using the 2015 FIGO guidelines for intrapartum fetal monitoring. Eur J Obstet Gynecol Reprod Biol 205: 27-31.
4. Each Baby counts 2015 full report. RCOG

5. 5. Confidential Enquiry into Stillbirths and Deaths in Infancy (CESDI). 5th Annual Report. London: Maternal \& Child Health Consortium, 1998.

6. The Dirty Dozen Errors in Maintenance.

7. Human Factors in Healthcare Trainer Manual (2016) Global air training limited.

8. Chandraharan E, El Tahan M, Pereira S (2016) Each Fetus Matters: An Urgent Paradigm Shift is needed to Move away from the Rigid "CTG Guideline Stickers" so as to Individualize Intrapartum Fetal Heart Rate Monitoring and to improve Perinatal Outcomes. International Journal of Obs and Gyn 5(4): 00168.

9. McDonnell S, Chandraharan E (2013) The Pathophysiology of CTGs and Types of Intrapartum Hypoxia. Current Women's Health Reviews. DOI: $10.2174 / 157340480903140131111654$.

10. Institute of Medicine (2008) Duty Hours: Enhancing Sleep, Supervision, and Safety. Washington, DC: The National Academies Press.

11. Flight safety foundation NBAA. April 2014. Duty/Rest guidelines for business aviation.

12. Martin P, Cortina-Borja M, Newburn M, Harper G, Gibson R, et al (2018) Timing of singleton births by onset of labour and mode of birth in NHS maternity units in England, 2005-2014: A study of linked birth registration, birth notification, and hospital episode data. PLoS One 13(6): e0198183.

13. Pereira S, Chandraharan E (2017) Recognition of chronic hypoxia and pre-existing foetal injury on the cardiotocograph (CTG): Urgent need to think beyond the guidelines. Porto biomedical journal 2(4): 124-129.

14. Wijemanne A, Chandraharan E (2016) RCOG World Congress June 2016. Role of reduce the impact of the Human WORM on poor perinatal 


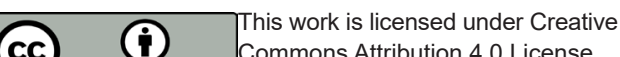
Commons Attribution 4.0 License DOI: 10.19080/GJORM.2018.06.555683
Your next submission with Juniper Publishers will reach you the below assets

- Quality Editorial service

- Swift Peer Review

- Reprints availability

- E-prints Service

- Manuscript Podcast for convenient understanding

- Global attainment for your research

- Manuscript accessibility in different formats

( Pdf, E-pub, Full Text, Audio)

- Unceasing customer service

Track the below URL for one-step submission https://juniperpublishers.com/online-submission.php 